\title{
Adsorbent Material Used In Water Treatment-A Review Chunguang $\mathrm{Yu}^{\mathrm{a}}$, Xuena Han \\ Harbin Commercial University, Harbin 150028, China. \\ aspringsun2015@qq.com
}

Keywords: adsorbent ; zeolite; activated carbon; clay minerals; industrial waste

\begin{abstract}
Adsorption method of purify water relies mainly on the adsorbent to adsorb the impurities in the water, this paper introduces the latest research progress both at home and abroad, such as activated carbon, chitosan, zeolites, clay minerals plant-based, industrial waste . These adsorbent type will play a more and more important role in water treatment in the future.
\end{abstract}

\section{Introduction}

More and more researchers pay attention to water pollution, the researchers use various methods to purify the polluted water, such as chemical precipitation, biological membrane method, electrochemical method and so on ${ }^{[1-3]}$. In these methods, adsorption method using various materials for water purification, because of its good processing effect, low cost, less secondary pollution to the environment, Adsorption method are popular with everyone. Adsorption method relies on various materials as adsorbent for purifying water, commonly used adsorbent is activated carbon, chitosan, zeolite, clay minerals that plant-based and industrial wastes, etc.

\section{Activated carbon}

Activated carbon is the most widely used method, the oldest known adsorbent. The adsorption principle is through the surface void to physical adsorption of heavy metal ions. Its surface area can reach $500-2000 \mathrm{~m}^{2} / \mathrm{g}$. Activated charcoal can absorb various heavy metals in water ${ }^{[4 ; 5]}$. The preparation of activated carbon materials are usually coal, coconut shell, lignite, and timber, commonly used physical and the chemical method to product activated carbon. Physical preparation method is carbonized materials will be at high temperatures, form long-short activated carbon. Chemical preparation method is to add chemical reagents to carbonized materials. Activated carbon for water treatment there are two main forms: powder activated carbon (PAC) and granular activated carbon (GAC). Most of the activated carbon removal of contaminants is the GAC. The commercial use of activated carbon was invented for a patent in 1900 and $1900^{[6]}$. In the United States, the activated carbon used in water supply for the first time was in 1928. Activated carbon has the advantage of simple operation, but the price higher defects will not be able to make their application to a wider range.

\section{Chitosan}

People pay more attentions to chitosan because the chitosan has very strong adsorption capacity of heavy metals and low cost. Some Asian countries such as Japan, Thailand, China's fishery wastes such as shrimp shell, crab shells were used to produce chitosan. Because the fish waste source is rich, so chitosan is cheap.

The yield of Chitin is one of the world's second-largest biological polymer, second only to cellulose. Chitosan is more important than the chitin, the molecular structure is similar to cellulose. At present, the chitosan attracted much attention due to its adsorption ability is strong. Chitin modified by alkali then take off the deacetylation form chitosan, it mainly exist in the exoskeletons of crustaceans. In recent years, many researchers study on a large amount of chitosan. In 1988, someone use of chitosan to remove cadmium for the first time, the adsorption capacity of $5.93 \mathrm{mg} / \mathrm{g}$, the best 
$\mathrm{pH}$ is $4.0-8.3^{[7]}$. The result is Similar to using chitosan adsorption of heavy metal study ${ }^{[8]}$, chitosan adsorption $\mathrm{Hg}^{2+}, \mathrm{Cu}^{2+}, \mathrm{Ni}^{2+}, \mathrm{Zn}^{2+}$ is $815,222,164,75 \mathrm{mg} / \mathrm{g}$ respectively, and the maximum absorbance of. Peniche -Covas $\mathrm{C}$ on the adsorption study of $\mathrm{Hg}^{2+[9]}$, the maximum number of adsorption of chitosan is $430 \mathrm{mg} / \mathrm{g}$. Difference is that the latter two kinds of the adsorption quantity of chitosan with particle size of $1.252 .5 \mathrm{~mm}(0.21-1 \mathrm{~mm})$, increases the surface area, high adsorption capacity. Chitosan was used to studied the hexavalent chromium ion ${ }^{[10]}$, the results showed that chitosan in $\mathrm{pH}$ $=4.0$, Chitosan adsorption capacity can reach $273 \mathrm{mg} / \mathrm{g}$. Chemical modification of chitosan is gradually being used to remove heavy metal ions. Someone use modified chitosan adsorption lead, adsorption capacity is $450 \mathrm{mg} / \mathrm{g}^{[11]}$.

\section{Zeolite}

Zeolite is a common mineral adsorbent, the adsorption characteristics lies in the power of the ion exchange. The structure of the zeolite has a lot of space, can undertake ion exchange with other metal ions. Original zeolite is aluminate crystals, nature is composed of oxygen atoms connected tetrahedron structure. In the $80 \mathrm{~s}$, zeolite because of its strong ability of ion exchange began to attract the attention of people, zeolite, including a lot of kinds, such as clinoptilolite, ling zeolite. The earliest use of it for metal strontium and cesium adsorption was studied ${ }^{[12]}$, in more than 40 clinoptilolite zeolite content is the most abundant in nature. Clinoptilolite has a strong adsorption capacity of heavy metals to adsorb $\mathrm{Pb}^{2+}$ and $\mathrm{Cd}^{2+}, \mathrm{Zn}^{2+}$ and $\mathrm{Cu}^{2+}$ ions ${ }^{[13]}$. Someone with clinoptilolite adsorbed $\mathrm{Pb}^{2+}$ and $\mathrm{Cd}^{2+}$ ions, the adsorption capacity were $1.4 \mathrm{mg} / \mathrm{g}$ and $\left.1.2 \mathrm{mg} / \mathrm{g}^{[14]}\right]$.

Studies have shown that the higher temperature can improve the adsorption ability of clinoptilolite

${ }^{[15]}$. Many researchers have studied the zeolite cation exchange capacity. Improve the ability of zeolite cation exchange capacity depends on the pretreatment method ${ }^{[16]}, \mathrm{NaOH}$ treatment of zeolite to improve the adsorption efficiency, with its ability to adsorb $\mathrm{Pb}^{2+}$ and $\mathrm{Cd}^{2+}$ more than $100 \mathrm{mg} / \mathrm{g}$, higher than that of untreated zeolite.To sum up, zeolite have potential as a substitute for activated carbon. But zeolite low permeability, in the practical application of the need for artificial transformation.

\section{Clay Minerals}

Coal mainly includes natural class performance of peat, lignite, etc., are rich in humic acid. They can be processed as adsorbent. Humic acid can be prepared corresponding resins as adsorbent, can a wide range of adsorption of heavy metal ions.Coal used for adsorption of $\mathrm{Cd}^{2+}$ ions ${ }^{[17]}$, the adsorption amount of $0.91 \mathrm{mg} / \mathrm{g}$, follow the Freundlich adsorption process model. When $\mathrm{PH}>10$, because form soluble small led to the decrease of the adsorption quantity of hydrogen and oxygen compounds. Similar reports, the use of coal adsorption $\mathrm{Hg}^{2+}$ ions ${ }^{[18]}$, the results show that use of nitric acid for pretreatment of coal can improve the adsorption ability, $\mathrm{Hg}^{2+}$ ions and adsorption sites of adsorption reaction speed, adsorption occurred on the surface of coal, $\mathrm{pH}$ between 7.0- 8.5, adsorption quantity can reach $10 \mathrm{mg} / \mathrm{g}$.

In the early days of the culture, the clay is the most understanding and common people, due to its low price, abundant raw material sources, and ions change with improving performance and potential, on the clay will be the best candidate as an adsorbent material, clay has a lot of different types. As clay adsorbent are most bleaching clay, followed by montmorillonite and a small amount of kaolin, clay adsorption and eventually in the mineral structure change, the change to the change of the clay adsorption ability to provide a large space, in recent years, in the clay minerals are increasing such as montmorillonite, kaolin, diatomite and bleaching earth, not only changed the inorganic part but also includes the organic molecules. 


\section{Industrial wastes}

Thermoelectric factory produce dust, it is the cheapest adsorbent, has a strong adsorption ability, such as copper ions ${ }^{[19]}$, in the $\mathrm{pH}=8.0,1.39 \mathrm{mg} / \mathrm{g}$ can adsorb $\mathrm{Cu}^{2+}$ ions. Dust and calcium silicate with 1:1 mixing, can adsorption $\mathrm{Cr}^{6+}$ ion, at the time of $\mathrm{pH}=2.0$, adsorption capacity up to $2.92 \mathrm{mg} / \mathrm{g}$, abide by the Langmuir adsorption process model, the hybrid adsorbent than dust - clay mixed adsorbent adsorption ability is strong, the latter the adsorption quantity of only $0.31 \mathrm{mg} / \mathrm{g}$.Study shows that after the dust adsorption of heavy metals is easy to cure, but because of the dust itself may contain heavy metals, to be removed in advance.Industrial waste is another kind of low-cost adsorbent of heavy metals, need certain process carries on the processing and improve its adsorption capacity. Different waste such as mud, lignin, iron hydroxide, red mud is used to remove the heavy metals in the wastewater.

\section{Summary}

Although the application of activated carbon is very wide, it is expensive. At the same time it need to complex auxiliary means to improve its adsorption ability. Therefore, in terms of economic reasons, activated carbon can't be used in factories. To sum up, chitosan has a strong adsorption capacity of heavy metals, mainly due to chitosan has a strong hydrophilic, hydroxyl content rich; There are a large number of amino groups has the acid; Adsorption of heavy metals is rich aggregate structure.Clay in practical industrial application, expansion coefficient is an issue to consider, because of its special structural characteristics and mechanism of ion exchange, may cause stress.

\section{Acknowledgements}

The authors thank The Doctor Research Projects of Harbin commercial university (Project Number: 13DL009) for the financial support to this project.

\section{References}

[1] Matlock M M, Howerton B S, Atwood D A. Irreversible precipitation of mercury and lead[J]. Journal of hazardous materials, 2001, 84(1)73-82.

[2] Sulzbacher K, Ecke H, Lagerkvist A, et al. Anaerobic reduction of hexavalent chromium in filter sludge of an electrochemical process[J]. Environmental Technology, 1997, 18(3)301-307.

[3] Yang F, Pecina D A, Kelly S D, et al. Biosequestration via cooperative binding of copper by Ralstonia pickettii[J]. Environmental Technology, 2010, 31(8-9)1045-1060.

[4] Carrott P J M, Carrott M M L R, Nabais J M V, et al. Influence of surface ionization on the adsorption of aqueous zinc species by activated carbons[J]. Carbon, 1997, 35(3)403-410.

[5] Gabaldon C, Marzal P, Alvarez-Hornos F J. Modelling Cd(II) removal from aqueous solutions by adsorption on a highly mineralized peat. Batch and fixed-bed column experiments[J]. Journal of Chemical Technology and Biotechnology, 2006, 81(7)1107-1112.

[6] Li C X, Lu Y Z, Que Y, et al. Removal of Chloroform from Hydrochloride Acid Solution Using Fine Powder of Polymer as Adsorbent[J]. Chinese Journal of Chemistry, 2009, 27(4)768-772.

[7] Rafatullah M, Sulaiman O, Hashim R, et al. Removal of cadmium (II) from aqueous solutions by adsorption using meranti wood[J]. Wood Science and Technology, 2012, 46(1-3) 221-241.

[8] Maleki A, Pajootan E, Hayati B. Ethyl acrylate grafted chitosan for heavy metal removal from wastewater: Equilibrium, kinetic and thermodynamic studies[J]. Journal of the Taiwan Institute of Chemical Engineers, 2015, 51(0)127-134.

[9] Li C B, Hein S, Wang K. Biosorption of chitin and chitosan[J]. Materials Science and Technology, 2008, 24(9)1088-1099.

[10] Hu X J, Wang J S, Liu Y G, et al. Adsorption of chromium (VI) by ethylenediamine-modified cross-linked magnetic chitosan resin: Isotherms, kinetics and thermodynamics[J]. Journal of hazardous materials, 2011, 185(1)306-314. 
[11] Chen C Y, Yang C Y, Chen A H. Biosorption of $\mathrm{Cu}(\mathrm{II}), \mathrm{Zn}(\mathrm{II}), \mathrm{Ni}(\mathrm{II})$ and $\mathrm{Pb}(\mathrm{II})$ ions by cross-linked metal-imprinted chitosans with epichlorohydrin[J]. Journal of Environmental Management, 2011, 92(3)796-802.

[12] Rao S V S, Lal K B, Narasimhan S V, et al. Copper ferrocyanide polyurethane foam as a composite ion exchanger for removal of radioactive cesium[J]. Journal of Radioanalytical and Nuclear Chemistry, 1999, 240(1)269-276.

[13] Smith J A, Tillman F D, Bartelt-Hunt S L, et al. Evaluation of an organoclay, an organoclay-anthracite blend, clinoptilolite, and hydroxy-apatite as sorbents for heavy metal removal from water[J]. Bulletin of Environmental Contamination and Toxicology, 2004, 72(6)1134-1141.

[14] Trgo M, Medvidovic N V, Peric J. Application of mathematical empirical models to dynamic removal of lead on natural zeolite clinoptilolite in a fixed bed column[J]. Indian Journal of Chemical Technology, 2011, 18(2) 123-131.

[15] Mamba B B, Nyembe D W, Mulaba-Bafubiandi A F. The effect of Si and Fe impurities on the removal of $\mathrm{Cu}(2+)$ and $\mathrm{Co}(2+)$ from $\mathrm{Co} / \mathrm{Cu}$ aqueous solutions using natural clinoptilolite as an ion-exchanger[J]. Desalination and Water Treatment, 2010, 21(1-3) 335-345.

[16] Stojakovic D, Milenkovic J, Daneu N, et al. A Study of the Removal of Copper Ions from Aqueous Solution Using Clinoptilolite from Serbia[J]. Clays and Clay Minerals, 2011, 59(3) 277-285.

[17] Snape C E, Lakatos J, Brown S D. Coals as sorbents for the removal and reduction of hexavalent chromium from aqueous waste streams[J]. Fuel, 2002, 81(5)691-698.

[18] Snape C E, Lakatos J, Brown S D. Application of coals as sorbents for the removal of Cr from aqueous waste streams[J]. Environmental Geochemistry and Health, 2001, 23(3) 287-290.

[19] Paperi R, Micheletti E, De Philippis R. Optimization of copper sorbing-desorbing cycles with confined cultures of the exopolysaccharide-producing cyanobacterium Cyanospira capsulata[J]. Journal of Applied Microbiology, 2006, 101(6)1351-1356. 